International Journal of Advanced Academic Studies 2020; 2(3): 345-349

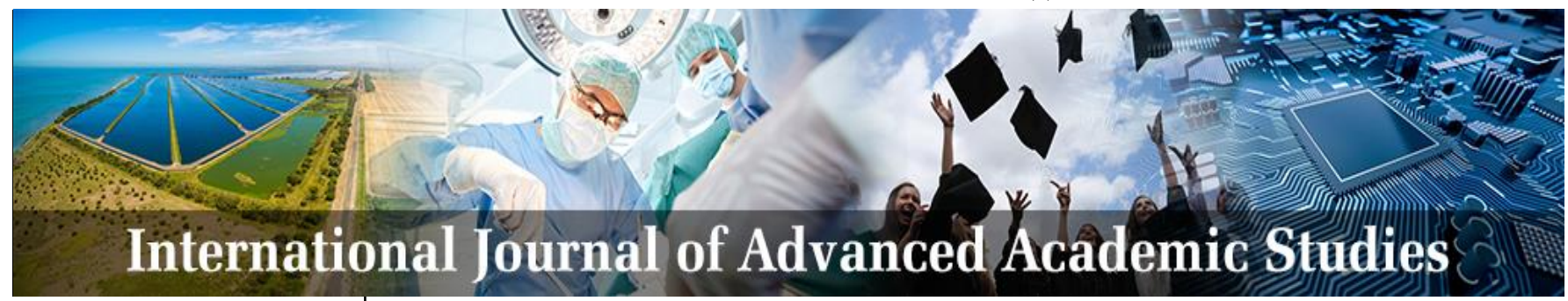

E-ISSN: 2706-8927

P-ISSN: 2706-8919

www.allstudyjournal.com

IJAAS 2020; 2(3): 345-349

Received: 10-05-2020

Accepted: 20-06-2020

Mahmood Usmanyar Assistant Professor,

Department of Foreign

Languages, Faculty of Electro

Mechanics, Kabul Polytechnic

University, Kabul,

Afghanistan

\section{A comparative study of Dari Persian and English language pure vowel sounds}

\author{
Mahmood Usmanyar
}

DOI: $\underline{\text { https://doi.org/10.33545/27068919.2020.v2.i3e.174 }}$

\section{Abstract}

In this research article, the pure vowel sounds (Monophtongs) of Dari Persian language have been compared with the pure vowel sounds of English language. The purpose of this research is to find the differences and similarities between the monophtongs of Dari Persian and English language which is useful for teachers as well as the students of both languages in listening and speaking skills. For conducting this research, qualitative method has been used by giving the three term description for each and every vowel sound of both languages and then compared to find out the differences and similarities. As a result, in this research article, it was found out that English language has twelve pure vowels, whereas Dari Persian language has eight pure vowels. This indicates that out of 12 , there are nine pure vowel sounds in English language which are not present in Dari Persian language at all. Nonetheless, the rest three vowels of English are into some extent similar to the three vowels in Dari Persian language; such as: /i:/, /u:/, and /a:/. Similarly, out of the eight pure vowels in Dari Persian language, there are 5 pure vowels which are not present in English language at all. Moreover, there are three central vowels in English, but Dari Persian language does not have any central vowel sound. It is believed that grown-up people cannot pick up the characteristic sound of a foreign language as much as children do. This is because the habits of one's own language are so strong that they are very difficult to break. In other words, the sounds in one's mother tongue, just like the structure of language influence the foreign language which in most cases causes miscommunication or misunderstanding. Therefore, this research permits the teachers to help students of English language as a foreign language and vice versa to be good listeners and make effective communication especially with the native speakers. Also, this research article will tempt the teachers to design some class activities or exercises for better pronunciation of students with more focus on the vowels which are not present in the first language.

Keywords: Difference between English and Dari Persian vowels, Similarities between English and Dari Persian vowels. Dari Persian vowel sounds, Dari Persian Monophthongs, Dari Persian pure vowels. Three terms description of Dari Persian vowels

\section{Introduction}

Language is a means of communication. In other words, people use language in order to convey their thoughts and feelings to each other. One of the means of communication is oral in which listening and speaking skills play an important role. When it comes to speaking, it is believed that pronunciation is a very difficult component in second or foreign language learning. Therefore, this research finds out what differences and similarities there are between English and Dari Persian vowels (Monophthongues) sounds. This research article is crucially important for enhancing better pronunciation in speaking and being a good listener for better understanding to teachers and learners of both languages. English teachers in Afghanistan can supplement their teaching materials with some pronunciation exercises focusing on the sounds which are either very different or not present in either of the languages at all. Moreover, this research article has an importance for English native speakers who learn Dari Persian language for effective speaking and being good listeners for better communication.

Linguists believe that mother tongue influences second language, especially one's mother tongue pronunciation habits affect pronunciation of second language. Therefore, this research article answers the following questions:

- Which English and Dari Persian monophthongue sounds are different?

- Which English and Dari Persian monophthongue sounds are similar?

- What are the English monophthongues which are not present in Dari Persian and vice versa?

\section{Mahmood Usmanyar}

Assistant Professor, Department of Foreign Languages, Faculty of Electro Mechanics, Kabul Polytechnic University, Kabul, Afghanistan 
- What is the three term label for each and every monophthogue of both languages described?

\section{Objective}

This research article compares the pure vowel sounds of English and Dari Persian language in order to find out the differences and similarities.

\section{Methodology}

In this research article, qualitative method has been used for the data collection by giving the three term description for vowel sounds of both languages.

\section{Literature Review}

As clear and understandable pronunciation has been one of the crucially important components of learning a second language, many researches have been conducted in this regard. For instance, a research "Perceptual Confusions of American English Vowels and Consonants by Native Arabic Bilinguals" was conducted in the United Arab Emirates. For this research, the researchers investigated the perception of American English sounds by young adults who were either early Arabic-English bilinguals whose native language was Arabic or they were native speakers of the English dialects spoken in the United Arab Emirates (UAE), where both groups were studying. The result of the research showed that for both informant groups the least accurately identified vowels were $/ \mathrm{a} /, / \mathrm{s} /, / \mathfrak{m} /$, while most consonant errors were found for $/ ð /$. The finding of the research demonstrates that one of the reasons for the lack of accuracy in several sounds of English was the considerable variation in their native and second language dialectal backgrounds (Robinson et al, 2013).

Sülükçü (2018) identified problems of pronouncing Turkish sounds by Arabic native speakers. All of the informants were refugees who learned Turkish language as a second language in Turkey in a private course. As a result, it was determined that the students experienced difficulties in pronouncing some 15 out of 21 consonants and 6 out of 8 vowels. The researcher recommended to focus more on the determined sounds in Turkish language classes for Arabic native speakers.

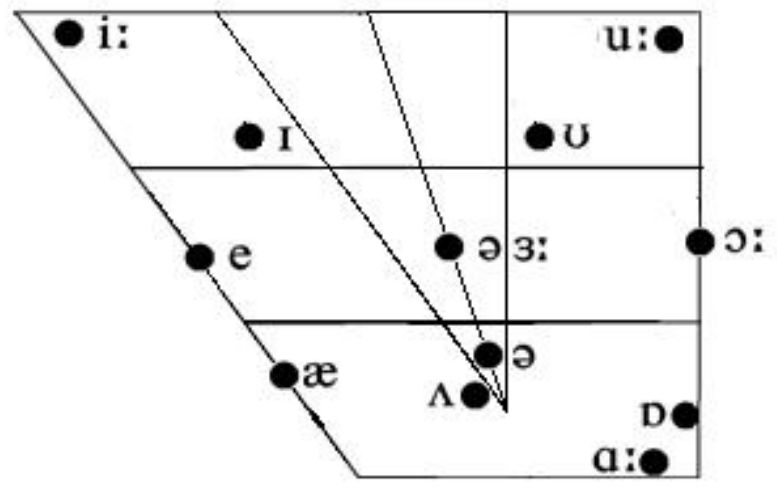

Fig. 1: (Roach, 2019, P.13) ${ }^{[7]}$
Therefore, the current research article compares Dari Persian and English vowel sounds to find out similarities and differences between them and recommend focusing more on those sounds in language classrooms that are either very different or not present in each other's sound system. Also, this research article will help language teachers to add some more pronunciation exercises to their teaching materials.

\section{Comparison of Dari Persian and English Language Pure Vowel Sounds}

In every language, there are limited numbers of distinctive units of sounds. They are the smallest units in the sound system of a language which distinguish one word from another. They are called 'phonemes' (Yadugari, 2008) ${ }^{[11]}$.

Speech sounds of all languages are classified, first and foremost, into vowels and consonants (Eshraqi, 2007) ${ }^{[2]}$. In the production of vowels, air comes out from the lungs in a continuous stream. There is no closure or narrowing in the oral cavity that would cause friction. Since the vocal cords vibrate to produce voice, all vowels are voiced sounds (although some languages have been analyzed as having voiceless vowels, e.g. Portuguese (Crystal, 2007).

Vowel sounds are also of two types: pure vowels and glide vowels (diphthongs and thriphthongs). In this research article, only pure vowels (Monophthongues) of the two languages are compared. Monophthongs refer to pure vowels for which there is no detectable change in quality in a syllable. Moreover, every language undergoes changes. English also has undergone many changes in spelling, vocabulary and pronunciation. Further, English is spoken worldwide as a first language or a second/official language. Therefore, there are many accents of English. For my research article, I am using RP, the standard accent, as a reference model. RP refers to Received Pronunciation, recently known as $\mathrm{BBC}$ pronunciation which is one of the standard varieties of English around the world and is most often recommended for foreign learners studying British English (Roach, 2019) ${ }^{[7]}$.

Roach (2019) ${ }^{\text {[7] }}$ in figure 1 has stated that there are 12 monophthongs in English language. However, Yamin (2007), as shown in figure 2 has said that there are 8 monophtongs in Persian language.

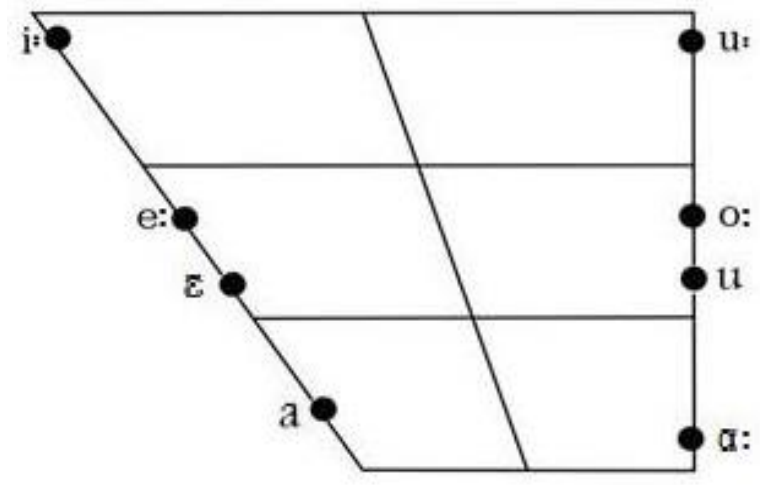

Fig. 2: (Yamin, 2015, P.45) ${ }^{[10]}$ 
Also, Yamin (2015) ${ }^{[10]}$ listed all the eight monophtongs of the Persian language in the following manner:

Table 1: (Yamin, 2015, P.44) ${ }^{[10]}$

\begin{tabular}{|c|c|c|c|c|c|}
\hline \multirow{2}{*}{ In terms of the quality of the sound } & \multicolumn{2}{|c|}{ In terms of the position } & Front & \multicolumn{2}{|c|}{ Back } \\
\cline { 2 - 5 } & $\begin{array}{c}\text { of the } \\
\text { tongue }\end{array}$ & Shape of the lips & Unrounded & Rounded & Unrounded \\
\hline \multirow{2}{*}{ Long } & Close (high) & i: & u: & \\
\cline { 4 - 6 } & \multirow{2}{*}{ Mid } & e: & o: & \\
\cline { 4 - 6 } & \multirow{2}{*}{ Short } & & $\varepsilon$ & U & \\
\hline Long & \multirow{2}{*}{ Open (low) } & & & $\mathrm{a}$ \\
\hline
\end{tabular}

After having a look at figures $1 \& 2$, and table 1 , we can draw the following table:

Table 2: (Designed by me, 2020)

\begin{tabular}{|c|c|c|c|c|c|}
\hline \multicolumn{2}{|c|}{ Front } & \multicolumn{2}{|c|}{ Central } & \multicolumn{2}{|c|}{ Back } \\
\hline English & Persian & English & Persian & English & Persian \\
\hline $\begin{array}{l}\mathrm{i}: \\
\mathrm{I}\end{array}$ & i: & - & - & $\begin{array}{l}\text { u: } \\
\text { U }\end{array}$ & $\mathrm{u}:$ \\
\hline $\begin{array}{l}\mathrm{e} \\
æ\end{array}$ & $\begin{array}{l}\mathrm{e}: \\
\varepsilon\end{array}$ & $\begin{array}{l}3: \\
\Lambda \\
\partial\end{array}$ & - & $\begin{array}{l}0: \\
\mathrm{p}\end{array}$ & $\begin{array}{c}\mathrm{o}: \\
\mathrm{u}\end{array}$ \\
\hline- & $\mathrm{a}$ & - & - & $\mathrm{a}:$ & $\mathrm{a}:$ \\
\hline
\end{tabular}

Vowels can be distinguished as Front, Back and Central in terms of the position of the tongue. The vowels in the production of which the front part of the tongue is raised are called front vowels. The vowels in the production of which the back part of the tongue is raised are called back vowels. Similarly, the vowels in the production of which a part of the tongue between the front and the back is raised are called central vowels (Roach, 2019) ${ }^{\text {[7] }}$. Please see Figure 3 for different parts of tongue. As seen in table 2, English has 4 front, 3 central and 5 back vowels. However, Persian has 4 front vowels and 4 back vowels. There is no central vowel in Persian language.

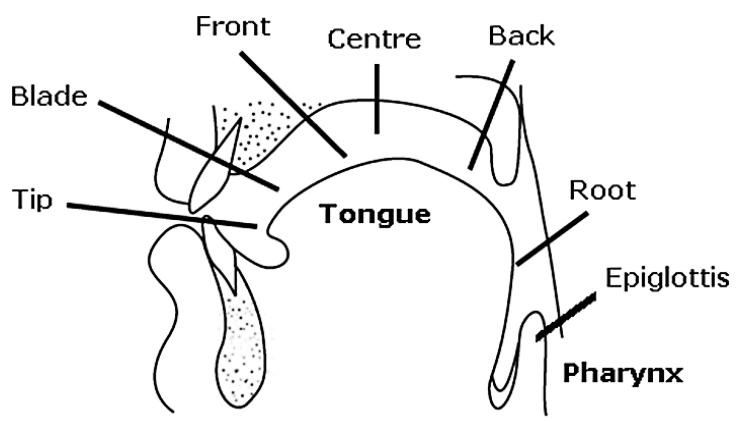

Fig. 3: (https://www.studyblue.com/20 July, 2020)

\section{Front Vowels of English and Persian}

Persian has four front vowels, so has RP (see Table 2). Out of these four front vowels, one vowel of RP is centralized. It is a short $/ \mathbf{I} /\left(\right.$ Roach, 2019) ${ }^{[7]}$. As against this, Persian does not have any central vowel (Yamin, 2015) ${ }^{[10]}$.

\subsection{Persian /i:/ and RP/i:/}

Both Persian / i:/ and RP / i:/ are front unrounded vowel just below close position (see Fig. 1 and Table1). Persian / i:/ is more close than RP/i:/.

\subsection{Persian /e:/ and RP /e/}

The only similarity these vowels share is their frontness, i.e. both are front vowels. They are quite different from each other otherwise. Persian /e:/ is a front unrounded vowel just below half-close (Yamin, 2015) ${ }^{[10]}$. However, RP /e/ is a front unrounded vowel between half-open and half-close (Roach, 2019) ${ }^{[7]}$. Moreover, Persian /e:/ is long (see Fig.2) and $\mathrm{RP} / \mathrm{e} /$ is a short vowel.

\subsection{Persian /E/ and RP / $/ \mathfrak{e}$}

Persian / $\boldsymbol{E} /$ is a front unrounded vowel just above half-open (Yamin, 2015) ${ }^{[10]}$, whereas RP/æ/ is front unrounded just below half-open (Roach, 2019) ${ }^{[7]}$. This three term descriptive label indicates that: RP/æ/ is more open than the Persian / $\boldsymbol{\varepsilon} /$.

\subsection{Persian /a/ and RP /æ/}

Persian /a/ is a front unrounded vowel just above the halfclose position (Yamin, 2015) ${ }^{[10]}$, while RP /æ/ is front unrounded vowel just below half open (Roach, 2019) ${ }^{[7]}$. Persian /a/ is more open than RP /a/.

\section{Persian and English back vowels}

There are four back vowels in Persian (Yamin, 2015) ${ }^{[10]}$, whereas RP has five back vowels (Roach, 2019) ${ }^{[7]}$. Table 2 indicates that out of the five back vowels, one back vowel of RP is centralized, whereas Persian does not have any back centralized vowel. Furthermore, RP has three long back vowels, so has Persian.

\subsection{Persian / u: /and RP / u: /}

Both Persian /u:/ and RP /u:/ are back close rounded vowels as well as long vowels. Fig. 1 and Table 1 indicate that Persian / $\mathbf{u}: /$ is more back than RP /u:/.

\subsection{Persian /o:/ and RP /o:/}

Persian /o:/ is a back rounded vowel below half-close position (Yamin, 2015) ${ }^{[10]}$, while RP is a back rounded vowel between half-open and half-close position (Roach, 2019) ${ }^{[7]}$. This leads us to say that Persian /o:/ is more close and more rounded than the RP /o:/.

\subsection{Persian / $\mathrm{u} /$ and RP / $\mathrm{p} /$}

Persian / $\mathbf{u} /$ is a back rounded vowel just above the halfopen position, whereas RP / $\mathbf{p}$ / is a back rounded vowel just above the open position. This description indicates that RP /p / is more open than the Persian /u /.

\subsection{Persian /a:/ and RP /a:/}

Persian /a:/ is a back unrounded vowel just above open (Yamin, 2015) ${ }^{[10]}$. RP /a:/ is also a back unrounded vowel just above open (Roach, 2019) ${ }^{[7]}$. They can be distinguished 
from each other only through the degree of backness. Persian /a:/is more back than RP /a:/.

\section{Central Vowels of English and Persian}

Central vowels are produced when the part of tongue between front and back is raised against the soft palate (Gimson, 1980). As it can be seen in Table 2, English language has three central vowels (Roach, 2019) ${ }^{[7]}$. In contrast, Persian language does not have any central vowels. In other words in terms of the position of the tongue, all Persian vowels are front and back (Yamin, 2015) ${ }^{[10]}$. According to Gimson (1980), the description for the three central vowels of English is given in the following manner:

- I $\mathbf{~ / ~ C e n t r a l ~ u n r o u n d e d ~ v o w e l , ~ b e t w e e n ~ h a l f - o p e n ~ a n d ~}$ open position.

- /3:/ Central unrounded vowel between half-close and half-open position.

- / a / Central unrounded vowel, between half-open and half-close position.

\section{Long and Short Vowels of English and Persian}

Based on the quality and length, vowels are distinguished as long and short vowels. Vowels that tend to be long, the symbols consist of one vowel symbol plus a length mark made of two dots (:). In English language out of 12, five vowels are long and the rest 7 vowels are short. In figure 1, it can be seen that the five long vowels of English have been marked with two dots. They are: / i:, 3:, u:, o:, a: / (Roach, 2019) ${ }^{[7]}$.

On the contrary, in Persian Language, out of 8, five are long and the rest three vowels are short. In Persian, the long vowels are also shown with the length mark. They are: / i:, e:, u:, o:, a: / (Yamin, 2015) ${ }^{[10]}$. See figure 2 again.

\section{Conclusion}

In this research article, English and Dari Persian monophthongues were compared in terms of quantity, quality, position of the tongue, and shape of the lips. Finally, it was found out that there is a huge difference between monophthogues of both languages. First, in terms of quantity, there are 8 monophthongues in Dari Persian; whereas English language has got 12 monophthogues. Secondly, in terms of quality and length, out of 12 , five are long and the rest seven monophthongues are short in English. However, out of 8, five are long and the rest three are short in Dari Persian language. These all five long monophthongues in both languages are quite different. Also, in terms of position of the tongue, English has front, back and central vowel sounds. In contrast, there is no any central vowel sound in Dari Persian vowel system. Dari Persian has only front and back vowels. Both English and Persian have 4 front vowels; however, the only slightly similar vowel is /i:/. In other words, all the other 3 front vowels are totally different. Similarly, English has 5 back vowels, but Persian has got only 4. Among all back vowels in both languages, the only slightly similar sounds are / u:/ and /a:/. Moreover, in terms of shape of the lips, in Persian language, four are rounded vowels and the rest four are unrounded. But English has four rounded and eight unrounded vowel sounds.

To sum up, slightly similar sounds between the two languages are: / i:/,/ u:/ and / a:/. In other words, all the other vowel monophthogues are quite different between the two languages. Therefore, there is no any similar sound between English and Dari Persian language. Please see the following table:

Table 3: (Designed by me, 2020.)

\begin{tabular}{|c|c|c|c|}
\hline Languages & Different sounds & Slightly Similar sounds & Similar sounds \\
\hline English & 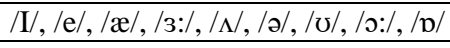 & \multirow{2}{*}{$\begin{array}{l}\text { / i:/ } \\
\text { / u:/ } \\
\text { / a:/ }\end{array}$} & - \\
\hline Dari Persian & /e:/, /o:/, /E/, /a/, /u/ & & $\begin{array}{l}- \\
- \\
-\end{array}$ \\
\hline
\end{tabular}

\section{Recommendation}

This research article which shows a vast difference between the vowel sounds of English and Dari Persian, makes the following recommendations:

- Teachers of the both languages are suggested to add more pronunciation exercises with more emphasis on the vowels which are either very different or not present in the second language.

- Teachers can adapt Text books' pronunciation exercises based on the information on this research article. In other words, the vowels which are not present in the second language should be considered and practiced more.

- All vowel sounds of Dari Persian language locate on the edge of the vowel diagram. Therefore, an acoustic analysis of Dari Persian vowels is required in order to locate all the vowel sounds on the vowel diagram more accurately.

- Similar research is required to find out the difference between diphthongs and consonants of English and Dari Persian language.
- Similar research is needed to be conducted on the difference between English and other National and official languages of Afghanistan.

- Another research needs to be done on the problems of pronouncing English vowels and/or consonant sounds by afghan speakers of English as foreign language.

\section{Reference}

1. Crystal, David. A dictionary of linguistics and phonetics. New York: Black Will Publishing, 2008.

2. Eshraqi, Sayed Ali Mohammad. Aaeen-e-Durust Nawisi. Kabul: Matba'aa-e-Balkh. Afghanistan, 2007.

3. Gimson AC. An introduction to the pronunciation of English. Hong Kong: Wing King Tong Co. Ltd., 1980.

4. Kartushina N. How and when does the second language influence the production of native speech sounds. Journal of Language Learning, 2016, 66(2).

5. O'connor JD. Better English pronunciation. Hyderabad: Replica Press Pvt. Ltd, 2007.

6. Richards, Jack C, Schmidt, Richards. Longman dictionary of language teaching and applied linguistics. London: Pearson Education Limited, 2002. 
7. Roach, Petter. English phonetics and phonology: a Practical course, 4th edn. Delhi: Cambridge University Press, 2019.

8. Shafiro, Valeriy. Confusion of American English vowels and consonants by native Arabic bilinguals. Journal of Language and Speech. 2013, 56(2).

9. https://www.studyblue.com/ 20 July, 2020

10. Yamin MH. Dastoor e Moaser e Parsi e Dari. Kabul: Entesharat e Maiwand, 2015.

11. Yadugari MA. Making sense of English: A text book of sounds, words and grammar. New Delhi: Vinad for Viva Books Private Limited, 2008.

12. Yule, George. The study of language, 6th edn. New York: Cambridge University Press, 2016.

13. Yusuf S. Determination of the Turkish language sounds that Arabic native speaker students experience problems with and proposed. Journal of Education and Training Studies, 2018, 6(11). 